\title{
Photoacid catalyzed organic-inorganic hybrid inks for the manufacturing of Inkjet-Printed Photonic Devices
}

\author{
Jorge Alamán, ${ }^{a, b}$ María López-Valdeolivas, ${ }^{a}$ Raquel Alicante, ${ }^{a}$ Francisco J. Medel, ${ }^{c}$ Jorge \\ Silva-Treviño, ${ }^{a}$ Jose Ignacio Peña, ${ }^{d}$ and Carlos Sánchez-Somolinos, ${ }^{a}$ e, *
}

\author{
${ }^{a}$ Instituto de Ciencia de Materiales de Aragón (ICMA), CSIC-Universidad de Zaragoza, \\ Departamento de Física de la Materia Condensada, Zaragoza, Spain \\ ${ }^{b}$ BSH Electrodomésticos España, S.A., Polígono Industrial de PLA-ZA, Ronda del Canal \\ Imperial de Aragón, 18-20, 50197 Zaragoza, Spain \\ ${ }^{\mathrm{c}}$ Instituto de Ciencia de Materiales de Aragón (ICMA), CSIC-Universidad de Zaragoza, \\ Departamento de Ingeniería Mecánica, Zaragoza, Spain \\ ${ }^{\mathrm{d}}$ Instituto de Ciencia de Materiales de Aragón (ICMA), CSIC-Universidad de Zaragoza, \\ Departamento de Ciencia y Tecnología de Materiales y Fluidos, Zaragoza, Spain \\ ${ }^{\mathrm{e}} \mathrm{CIBER}$ in Bioengineering, Biomaterials and Nanomedicine (CIBER-BBN), Spain \\ *Correspondence: carlos.s@csic.es
}

Keywords: Organic-Inorganic Hybrid Materials, Photoacid Generators, UVPhotopolymerization, Inkjet Printing, Waveguides. 


\begin{abstract}
Photoacid catalyzed jettable inks containing monomers with epoxy and silane functionalities has been successfully formulated. In contrast to inks based on conventional sol-gel processes, the hydrolysis and condensation process in these materials is triggered after printing using UV light this favoring the long-term stability of the ink, a requisite in industrial applications. UV light can trigger the photocuring reaction of the epoxy groups and the hydrolysis and condensation of the silane groups leading to a crosslinked organicinorganic hybrid polymeric network. Advantageously, the inks use no solvents and therefore the deposited material can be polymerized immediately after the deposition step by exposure to UV light. No additional baking steps are required allowing the use of thermally sensitive substrates and notably simplifying the process to one single step. Deposits with excellent adhesion and good transparency can be obtained by proper selection of the curing conditions through this process. Planar and channel optical waveguides have been prepared with these formulations using inkjet printing technology on a variety of substrates. The waveguides support optical modes with propagation losses as low as $0,5 \mathrm{~dB} / \mathrm{cm}$, demonstrating the potential of these photoacid catalyzed organic-inorganic hybrid formulations and inkjet printing for the preparation photonic devices.
\end{abstract}




\section{Introduction}

The controlled propagation of light along planar dielectric layers is a basic pillar for the implementation of integrated optical circuits ${ }^{1}$. Planar waveguides can act as optical interconnects between light sources and detectors in these photonic circuits or be themselves active elements such as amplifiers and lasers ${ }^{2-4}$. Far from being limited to signal processing and telecommunication applications, planar waveguides have a tremendous impact in the development of other technological fields. A large R\&D effort is being demanded towards the development of sensors based on planar-guided optics for environmental and biomedical monitoring, solar concentrators for energy harvesting or lighting devices such as backlights for displays ${ }^{5-8}$.

Hybrid organic-inorganic polymeric networks have demonstrated to be suitable materials for the preparation of planar optical waveguides ${ }^{2-3,9-17}$. Highly transparent films with precisely controlled thickness, requisite in this application, can be prepared from these materials and their refractive index adjusted by proper selection of the initial formulation and processing conditions $^{11,15}$. In addition, once prepared, they present excellent chemical and mechanical stability and good adhesion to inorganic substrates such as silicon and silicon oxide ${ }^{2,18}$. As a prevalent example, in the ORMOCER ${ }^{\circledR}$ materials, alkoxysilanes bearing organic polymerizable groups are used as precursors to prepare, through a sol-gel route, nanoscale inorganic oligomers decorated with reactive organic functionalities ${ }^{19}$. By incorporating suitable photoinitiators, structured waveguides can be prepared by applying the sol-gel processed material to a flat substrate and subsequently using photolithographic techniques (involving patterned UV-exposure, wet development and thermal curing steps) to crosslink and fix the organic part $3,10-12,15,20-22$. Despite the variety of light based patterning techniques available for fabrication, mainly mask and holographic lithographies or direct laser writing (DLW) are used. These usually lack (except DLW) of flexibility for the rapid prototyping of structures and devices and they always require wet etching and thermal baking steps making the overall process complex and precluding their use with heat and chemically sensitive surfaces. As a result, it is important to count with flexible fabrication techniques for the micromanufacturing of optical waveguides and their integration with other already processed optical elements and devices, all this being possible in different types of substrates.

Inkjet printing has demonstrated over the last years to be a powerful tool for the patterning of functional materials to implement elements and devices not only in optics and photonics but 
also in other application fields such as biomedicine, energy and electronics ${ }^{23-26}$. In contrast to conventional coating techniques, such as spin-coating or dip-casting, inkjet printing allows to finely structure the applied materials, beyond the preparation of continuous unstructured films. Compared to photolithography, that also enables patterning, inkjet printing allows to digitally deposit different functional materials at precise locations on virtually any type of substrate even non-flat or flexible ones. As an additional advantage compared to light based lithographies, inkjet printing requires minimal post-processing, eliminating wet etching steps and therefore being an environmentally friendly technique. All these features make inkjet printing a very attractive technology for the implementation of functional optical devices. For example, a great deal of control has been achieved in the preparation of microlenses in which numerical aperture and focal length can be controlled by using this technique becoming a simple and cost-effective alternative to existing methods ${ }^{27-33}$. In this context, there is a growing interest in the preparation of functional waveguides using additive manufacturing techniques, however the type and number of available materials for waveguide printing is quite limited ${ }^{34}$. Besides recently proposed stretchable materials obtained from polyurethane based inks ${ }^{35}$, other alternative systems are the commercial UV-curable solvent-containing hybrid organic-inorganic inks from Fraunhofer ISC and MicroResist technologies GmbH with excellent transparency and mechanical stability ${ }^{36}$. These solvent-containing acrylate based inks require soft baking step to eliminate the solvent prior to UV curing in nitrogen atmosphere and usually a post baking step is also carried out ${ }^{32,37-38}$. Acrylate solvent-free based inks have also been recently proposed by Hofmann and Bollgruen ${ }^{39-42}$.

Here we present new jettable solvent-free inks based on photoacid catalyzed formulations containing monomers with epoxy and silane functionalities. Recently this type of photoacid catalyzed polymerization reactions have demonstrated to be an efficient approach for the preparation of hybrid materials. Compared to other sol-gel methods it presents higher reactivity and it is a solvent-free process starting with the low molecular weight alkoxysilanes. Due to the presence of suitable photoinitiators in the formulation, UV irradiation induces the curing of the organic part. A subsequent thermal annealing step allows the formation of the inorganic network ${ }^{43-45}$. For certain formulations, the polymerization of the organic and inorganic networks can concomitantly take place in a very efficient manner, enormously simplifying the process and avoiding the use of postbaking steps ${ }^{46-48}$. We try to leverage the advantages of this reaction to generate novel low viscosity formulations suitable for inkjet printing and having tailored final properties. Compared to conventional hybrid inks 
based on prehydrolyzed-condensed reactive inorganic precursors, in the presented approach, hydrolysis and condensation is advantageously delayed (by protecting the ink from UV light) after the printing step favouring the long-term stability of the inks, a prerequisite for industrial applications. Once applied through inkjet printing, actinic UV light reaching photoacid generators (PAGs) included in the formulation induces the release of acids that catalyze both the cationic ring opening polymerization of epoxy groups and, in the presence of atmospheric water, the hydrolysis and condensation of organosilanes. The light triggered reaction of the two functional groups leads, under controlled processing conditions, to solid films with good adhesion and transparency without the need of any further postprocessing step. By including appropriate monomers in the formulation, high refractive index planar and channel waveguides with low propagation losses can be generated through this materialprocessing platform on a variety of substrates.

\section{Experimental Section}

Inks. Materials, ink preparation and characterization. The chemical structure of the main components of the ink is shown in Scheme S1 in the ESI. 3-glycidoxypropyltrimethoxysilane (GPTMS), a trialkoxysilane provided with an epoxy group, therefore having a hybrid organic and inorganic nature was acquired from Alfa Aesar. GPTMS is a low viscosity liquid at RT. The polymeric epoxy resin Epikote 157 (main component in SU-8 resists), with a monomer having an average of eight aromatic benzene rings and eight epoxide groups, was purchased from Momentive and it comes in solid form as flakes at RT. Dimethoxydiphenylsilane (dPDMS) is a liquid disilane monomer with two aromatic rings. Triarylsulfonium hexafluorophosphate salts (50\% in propylene carbonate) acquired from Aldrich act as a photoacid generator (PAG). Upon UV actinic illumination this compound leads to the formation of an acid $\left(\mathrm{H}^{+} \mathrm{X}^{-}\right.$, with $\left.\mathrm{X}^{-}=\mathrm{PF}_{6}{ }^{-}\right)$, that acts as a initiator for the organic epoxide groups polymerization as well as a catalyst for the hydrolysis and condensation of the alkoxides. BYK-333 is a polyether-modified polydimethylsiloxane supplied by BYK Chemie that strongly reduces the surface tension of the ink also favoring surface wetting. All the materials were used as received.

Two photocurable inks, namely a Model ink and a High Refractive Index (HRI) ink, were prepared by mixing different percentages of the above mentioned materials. To facilitate 
mixing, Epikote 157 was thoroughly grinded previous to its addition to the mixtures. These mixtures were stirred at room temperature (RT) using a magnetic stirrer at $600 \mathrm{rpm}$ until a transparent solution was achieved.

Viscosity measurements of the inks were carried out using a Rheometer HaakeMars, rotors DC60/11 of Thermo Scientific, Germany. Surface tension of the inks was characterized using an Attension Goniometer Theta Lite and using the pendant droplet method. The given values are the result of an average of three independent measurements. Density measurements were carried out using a $10 \mathrm{ml}$ pycnometer.

Substrates, cleaning and surface treatment. Conventional microscope glass slides with refractive index $n_{g}=1.514$ at $632.8 \mathrm{~nm}$ were employed for the HRI ink, however quartz substrates with refractive index $\mathrm{n}_{\mathrm{q}}=1.457$ were used for the Model ink deposits to prepare thin films of the materials.

Pre-cleaning of the substrates was performed by gently hand rubbing the surface using nitrile gloves and a solution of soapy water. After thoroughly rinsing the substrates with water, they were ultrasonicated with soapy water for $10 \mathrm{~min}$. Immediately after the substrates were refluxed with milli-Q water and ultrasonicated in milli-Q water for $10 \mathrm{~min}$. After the water cleaning step, the substrates were refluxed with isopropyl alcohol and ultrasonicated in isopropyl alcohol water for $10 \mathrm{~min}$. To finish, the substrates were immediately dried with compressed air and stored until their use.

UV Ozone treatment was performed with a UV-ozone reactor UVO 342 (Jelight company Inc., CA, USA) to remove any remaining organic contamination.

Pyrosil treatment was carried out by using combustion chemical vapor deposition (CCVD) using Pyrosil (Pyrosil ${ }^{\circledR}$, SURA). Briefly, an organosilicon precursor is injected into a gas flame that is put in short contact with the substrate leading to a $\mathrm{SiO}_{2}$-like coating with thickness typically below 50-100 $\mathrm{nm}$. As a result, important changes in the wettability and in the adhesion are obtained ${ }^{49}$.

Inkjet printing and drop observation. Inkjet printing was carried out using a custom-made inkjet printer system (In-2 Printing Solutions, Navarra, Spain) with Xaar-126/80 piezoelectric printheads (Xaar, Cambridge, United Kingdom). These printheads have 126 nozzles (50 $\mu \mathrm{m}$ diameter) arranged in a line with a pitch of $137 \mu \mathrm{m}$. The printhead is fixed in a frame and the 
substrate moves under the nozzles at a distance between the printhead and substrate of approximately $1 \mathrm{~mm}$. The line of nozzles is perpendicular to the direction of the substrate motion and as a result the vertical resolution (in the direction of the line of nozzles) is 185 dots per inch (dpi). The horizontal printing resolution (in the direction of the printhead motion) depends on the firing frequency and the speed of the substrate relative to the printhead. The printhead is commanded using Xaar XUSB drive electronics controlled with a PC using the corresponding software (from Xaar) that allows to control printhead parameters, sample detection and pattern to be printed (bitmap file). During printing operation the target substrate moves under the printhead at a constant speed (typically $20 \mathrm{~mm} / \mathrm{s}$ ) by using an eTrack linear stage from Newmark systems Inc. (Mission Viejo, CA, USA) commanded by IMS-Terminal software (Marlborough, CT, USA). The printhead is embedded in a metallic block with heater and a thermocouple connected to a temperature regulator that maintains the block near the desired set point. For the analysis of the characteristics of the ejected drops, a home-built dropwatcher system was used. This allows the characterization and optimization of the printing system configuration specially parameters that fix the voltage. This visualization system consists on a CCD camera, a strobe led device and a pulse generator to synchronize the piezoelectric signal, the strobe light and the camera acquisition events.

UV-curing fixation. An UV lamp Exfo OmniCure S2000 UV (Gentec, Nivelles, Belgium) has been employed with a UV bandpass filter (wavelength range of 320 - $390 \mathrm{~nm}$ ) A power of $10 \mathrm{~mW} / \mathrm{cm}^{2}$ was applied for curing during $5 \mathrm{~min}$. Unless it is specified, curing was carried in ambient atmosphere with relative humidity between $30-40 \%$ and at room temperature (25 ${ }^{\circ} \mathrm{C}$ ). Some of the samples were cured inside a chamber provided with an optical access. A mild vacuum (100 mBar) can be attained inside the chamber by using a vacuum pump. Once the desired pressure level is achieved, UV exposure is immediately carried out to minimize evaporation of the deposited ink components.

Characterization. Fourier Transform Infrared (FTIR) Spectroscopy was performed using a Perkin Elmer Spectrum 100 with ATR accessory. FTIR spectra were measured between $4000-450 \mathrm{~cm}^{-1}$.

UV-Vis absorption measurements of the solutions and the films were carried out using a VARIAN Cary-500 spectrophotometer. 
Optical Images of the deposited drops were taken using an optical microscope OLYMPUS Eclipse i80.

Thickness characterization of the deposited layers and profiles of the channel waveguides were characterized using a Bruker Dektak XT Stylus Profiler.

Surface morphology of the cured films was studied using a Field-Emission Scanning electron microscope (FE-SEM) Merlin Carl Zeiss (Germany). Atomic Force Microscope (AFM) images were obtained using a Ntegra Aura Scanning Probe Microscope from NT-MDT (Moscow, Russia) working in semi contact mode.

Mechanical properties of the films were characterized using a Nanoindenter G200 from Agilent Technologies equipped with a Vickers indentor tip. Measurements were carried out at RT and ambient atmospheric conditions using a continuous stiffness measurement method that applies a small load oscillation (displacement amplitude $2 \mathrm{~nm}$ ) superimposed to the applied load at frequency $45 \mathrm{~Hz}$. As a result hardness and elastic modulus are obtained as a function of the penetration depth during the loading-unloading cycle. A maximum penetration depth in the order of $10 \%$ the thickness of the film under study was performed so the values obtained are intrinsic of the material. Hardness and elastic modulus are obtained on the basis of the Oliver and Pharr method ${ }^{50}$ assuming a Poisson ratio of 0,38 as done by other authors for similar materials ${ }^{51,52}$. To eliminate any tip-rounding effect, the data from the first $100 \mathrm{~nm}$ is disregarded ${ }^{53}$. Below this depth data were consistent and mean values of hardness and elastic modulus were obtained by averaging data between $100 \mathrm{~nm}$ and $200 \mathrm{~nm}$, being the maximum penetration depth $400 \mathrm{~nm}$, (approximately 10\% of the film thickness). Values were calculated on the basis of 4 indentations in 2 identical samples.

Adhesion tests. Adhesion of the cured films to the substrate was characterized using a crosscut and tape test according to the ASTM D3359 standard method ${ }^{54}$. Briefly, in a first stage, six parallel scratches are made on the deposit by using a round cutter with 6 parallel blades (Neurtek) separated $1 \mathrm{~mm}$. The scratches are deep enough to reach the substrate surface. A cross-cut pattern of $6 \times 6$ cuts was created by applying, in a second stage, the cutter in a direction perpendicular to the first cut. After brushing the scratched area, a normalized adhesion tape (Tesa 4024) is applied over the crosscut pattern and quickly removed at an angle of $180^{\circ}$. The degree of adhesion is evaluated visually by examining the sample using an optical microscope. The adhesion strength is categorized by assessing the amount of deposit 
removed from 5B (strongest adhesion/no film removal) to $0 \mathrm{~B}$ (weakest adhesion/complete film removal). Adhesion experiments were reproduced in 3 samples for this adhesion assessment.

Optical characterization of the waveguides. The modes propagating in the planar waveguides were characterized using a prism coupler Metricon 2010 equipped with a HeNe laser at 632.8 $\mathrm{nm}$ for the transverse electric (TE) and transverse magnetic (TM) polarization. Essentially a laser beam reach a prism with high refractive index and it is reflected to a photodetector. The thin film is placed against the base of the prism and pressed using a pneumatic knee minimizing in this way the air gap between prism and sample. The ensemble is rotated with respect to the laser beam. When the angle matches that of the waveguided modes, coupling of light into the waveguide might occur which it is manifested by the decrease in the light intensity reaching the photodetector. These measurements allow to obtain the refractive index and film thickness of the films ${ }^{55}$. The propagation losses of the photopolymerized hybrid waveguides obtained by inkjet printing were also characterized using this same equipment. Briefly an optical fiber scans several $\mathrm{cm}$ of the surface where the light is propagating, detecting the scattered light that it is assumed to be proportional to the intensity of light propagating at each position. The intensity remaining in the waveguide after propagating a distance $\mathrm{x}$ is given by:

$\mathrm{I}(\mathrm{x})=\mathrm{I}_{0} 10^{\left(-\frac{\alpha \mathrm{x}}{10}\right)}$

where $I_{0}$ is the initial intensity, $I(x)$ is the transmitted intensity through the waveguide at a position $\mathrm{x}(\mathrm{cm})$, and $\alpha$ is the attenuation coefficient measured in decibels per centimeter $(\mathrm{dB} / \mathrm{cm})$.

\section{Results and discussion}

Ink preparation, jetting properties and ink deposition. Two different inks have been prepared and studied in this work (Table 1). First, we have explored a Model ink based on a simple formulation having as main component GPTMS, a hybrid precursor bearing an epoxide and a triethoxysilyl group. The ink is photosensitized by adding a percentage of $2 \mathrm{wt}$ $\%$. of triarylsulfonium hexafluorophosphate salts to the GPTMS. These salts show an excellent thermal stability and strong absorption in the $\mathrm{UV}^{56,57}$. In the absence of light the 
mixture is stable (photolatent system). Additionally $0.05 \mathrm{wt} \%$ of BYK-333 was added to improve the wetting of the ink in the substrate ${ }^{58}$.

A second ink has been prepared based on the same photochemistry but incorporating new monomers to rise the refractive index of the final deposit to be used as a planar waveguide. Besides 50 wt \%. of GPTMS, 25 wt \% of Epikote 157 and 25 wt \% of dPDMS were incorporated to this high refractive index (HRI) ink. Additionally $2 \mathrm{wt} \%$. of triarylsulfonium hexafluorophosphate salts and $0.05 \mathrm{wt} \%$ of BYK-333 were added as in the Model ink. Epikote 157 with eight benzene rings and eight epoxide groups is expected to join the organic part of the polymeric network, while dPDMS, with two benzene rings and two silane groups, the inorganic one. In both cases the aromatic rings will contribute to increase the refractive index of the final material.

Table 1. Composition of the Model and high refractive index (HRI) inks in wt \%. Additionally $2 \mathrm{wt} \%$. of triarylsulfonium hexafluorophosphate salts and $0.05 \mathrm{wt} \%$. of BYK333 were added as photoacid generator and surface tension modifier respectively to both inks.

\begin{tabular}{|c|c|c|c|}
\hline & GPTMS & EPIKOTE 157 & dPDMS \\
\hline Model ink & 100 & - & - \\
\hline HRI ink & 50 & 25 & 25 \\
\hline
\end{tabular}

Successful inkjet printing requires a full control of the process that essentially consists of the ejection of droplets of ink with controlled properties and their precise positioning and fixation on the final substrate. Starting with the drop ejection process, this involves the generation of a pressure pulse within the printhead that induces the formation of a jet leaving the nozzle. The printhead used in this study employs piezoelectric technology. A pulse of voltage is applied to the piezoelectric element placed close to a nozzle generating a pressure wave in the ink. If enough kinetic energy is transferred to the ink, the fluid can overcome the surface tension and generate a jet leaving the nozzle. The correct formation of ink droplets from this jet needs that this thins and breaks up leading to a single drop, what requires specific fluid properties. 
Surface energy, viscosity and density are the main ones. A series of non-dimensional numbers can be defined relating different magnitudes of the moving jet when leaving the printhead nozzle and help to identify favorable regimes for correct drop formation. In this way, Reynolds number (Re) relates inertial forces and viscosity while the Weber number (We) compares kinetic and surface energy of the leaving fluid. Ohnesorge introduced a nondimensional number that helps to identify the different regimes of the break up of a jet leaving an orifice. The Ohnesorge number $(\mathrm{Oh})$ relates Re and We and eliminates the speed of the fluid and therefore only depends on the properties of the ink and the dimensions of the orifice.

$\operatorname{Re}=\frac{\mathrm{v} \rho \mathrm{a}}{\eta}$

$\mathrm{We}=\frac{\mathrm{v}^{2} \rho \mathbf{a}}{\gamma}$

$\mathrm{Oh}=\frac{\sqrt{\mathrm{We}}}{\mathrm{Re}}=\frac{\eta}{\sqrt{\gamma \rho \mathrm{a}}}$

where $v$ is the speed of the ink leaving the nozzle, $\eta$ is the ink viscosity, $\gamma$ its surface tension, $\rho$ its density and a the diameter of the orifice.

To gain insight into the jetting process calculations of these non-dimensional numbers were carried out for the inks. Viscosity, surface tension and density of the prepared inks were characterized and the results are shown in Table 2. Values of surface tension measurements are obtained at RT $\left(26^{\circ} \mathrm{C}\right)$ slightly below the temperature of the printhead $\left(32{ }^{\circ} \mathrm{C}\right)$. We assume the values of surface tension do not significantly change in such a small range of temperature $\left(26-32{ }^{\circ} \mathrm{C}\right)$ taking the values at RT for the We and Oh numbers calculations. In both inks, the measured value of surface tension is around $27 \mathrm{mN} / \mathrm{m}$ that is mainly dictated by the presence of the polyether-modified polydimethylsiloxane BYK-333. Density is close to $1.1 \mathrm{~g} / \mathrm{cm}^{3}$ in both cases. Viscosity, that can have a strong dependence with temperature, was measured at $32^{\circ} \mathrm{C}$ the temperature of the printhead. The viscosity of the Model ink is quite close to that of its main component GPTMS almost unchanged by the addition of the photoinitiator and other additives. The incorporation of dPDMS and Epikote 157 into the 
HRI ink resulted in a more viscous solution. This rise in viscosity is mainly due to the addition of Epikote 157 that is an epoxy oligomer solid at RT known to lead to viscous solutions in organic solvents (e.g.: Epikote 157 based SU-8 viscous photoresists in cyclopentanone).

Table 2. Density, viscosity, surface tension, droplet speed and Re, We and Oh number values for Model and HRI inks. a) Measured at $32{ }^{\circ} \mathrm{C}$. b) Measured at $26^{\circ} \mathrm{C}$. c) Measured at optimum single droplet forming conditions. d) For Re, We and Oh calculations, surface tension values at $32{ }^{\circ} \mathrm{C}$ are approximated by those measured at $26^{\circ} \mathrm{C}$.

\begin{tabular}{|l|l|l|l|l|l|l|l|}
\hline & $\rho(\mathrm{g} / \mathrm{cm} 3)^{\mathrm{a}}$ & $\eta(\mathrm{mPas})^{\mathrm{a}}$ & $\gamma(\mathrm{mN} / \mathrm{m})^{\mathrm{b}}$ & $\mathrm{v}(\mathrm{m} / \mathrm{s})^{\mathrm{c}}$ & $\mathrm{Re}^{\mathrm{d}}$ & $\mathrm{We}^{\mathrm{d}}$ & $\mathrm{Oh}^{\mathrm{d}}$ \\
\hline Model ink & 1.06 & 3.44 & 27.44 & 1.70 & 26.2 & 5.58 & 0.09 \\
\hline HRI ink & 1.1 & 28.54 & 26.25 & 2.04 & 3.93 & 8.72 & 0.75 \\
\hline
\end{tabular}

Taking the diameter of the nozzle as $50 \mu \mathrm{m}$, the Oh numbers for each of the systems are also given in the table 2. With these figures and assumptions, the Ohnesorge numbers take values of 0.09 and 0.75 for the Model and HRI inks respectively. It is known from the literature that inks with Oh numbers between 0.1 and 1 typically lead to stable droplet formation ${ }^{59}$ Other authors give even narrower limits for this ejectability criterion (Oh numbers between 0.07 and 0.25 according to Moon and coworkers ${ }^{60}$ ). In both cases, our inks have acceptable values being within or very close to the established limits. Experimentally, we found, for both inks, that the application of a voltage to the piezoelectric actuators of the printhead slightly above certain threshold led to stable drop formation without satellites. Fig. 1 shows a sequence of photographs in which the drop formation process can be followed. Application of a voltage to the piezoelectric element of the printhead induces a jet that leaves the nozzle, thins and breaks up after some time. The long tail formed after jet breaking is completely retracted towards the main drop without breaking in satellites. For these optimum conditions the round droplets with no satellites have the speed shown in table 2 that corresponds to We and Re numbers given also in the same table. For these optimum conditions, We numbers for both inks are larger than the threshold of 4 (We $>4$ ) established by Duineveld and coworkers ${ }^{25,61}$. 
Application of higher voltages to the printhead led to a longer jet that ends up breaking up in a main droplet travelling at higher speed and one or several satellites following the first one (see Fig. S1). It is important to note that the low viscosity Model ink leads, in our printing system, to an $\mathrm{Oh}$ number close to the ejectability limit described in the literature. In this regime of low viscosity liquids there is a strong tendency to form satellites during jet break up which has not been observed in our case. The suppression of satellites in our case can be favored by the presence of the small percentage of the polymeric additive BYK-333. It is well known that the addition of small traces of polymeric additives introduces viscoelasticity in the ink. Besides the forces that, in Newtonian liquids, typically govern droplet formation from the initial jet (inertial and viscous forces and surface tension), elasticity also strongly influences the droplet formation process in fluids incorporating diluted polymers. Elastic forces in these systems arise from the extended polymeric chains along the elongated jet. Even at small percentages, the presence of these extended chains favors the retraction of the long tail formed after jet breaking towards the main drop precluding satellite formation ${ }^{62,63}$.

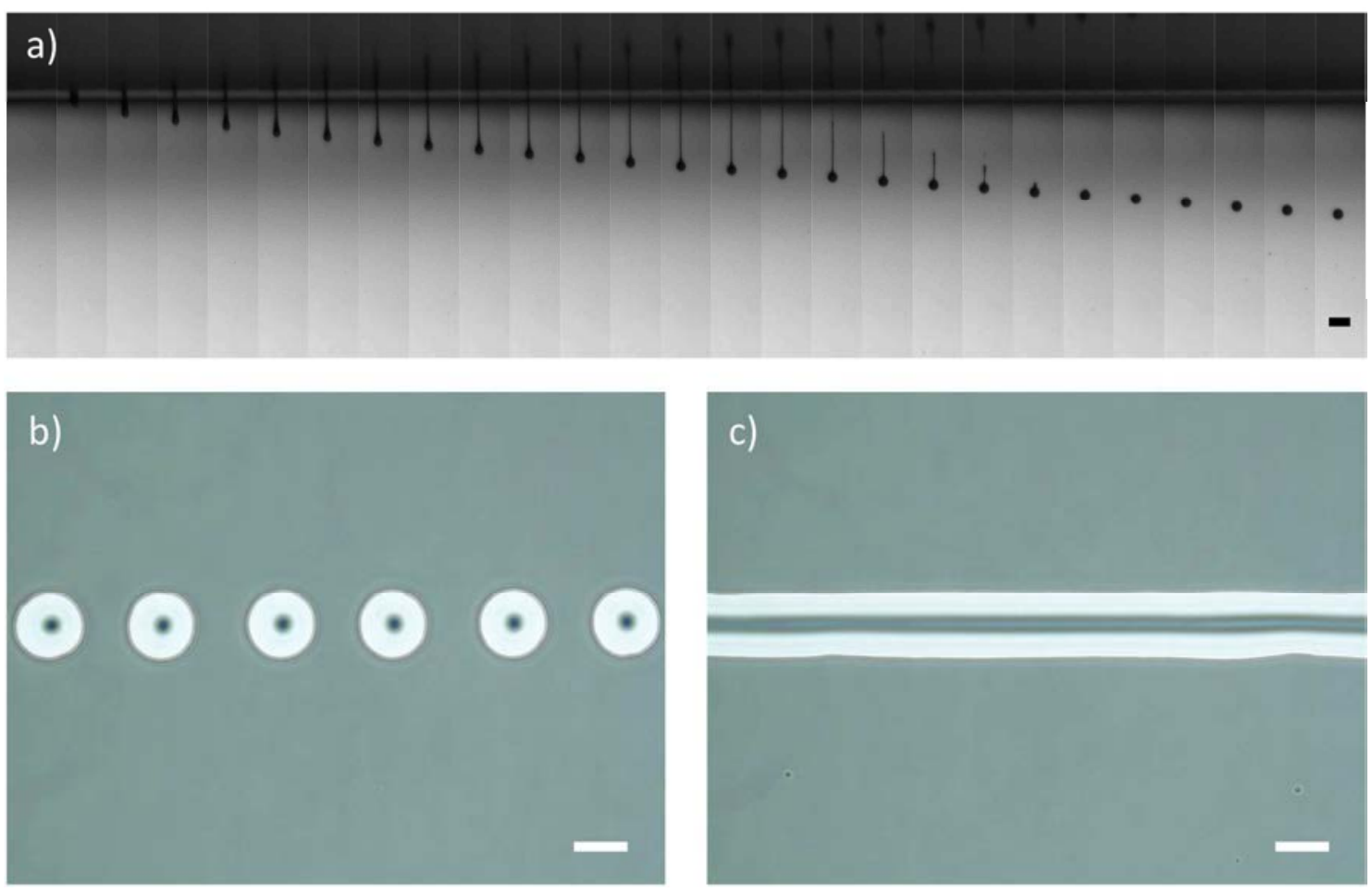

Fig. 1 (a) Temporal sequence of photographs (from left to right) showing the drop formation process for the HRI ink. The time interval between two adjacent frames is $8.5 \mu$ s (scale bar: $100 \mu \mathrm{m}$ ). (b and c) Phase contrast microscope images of the inkjet printed drops of HRI ink deposited along a line in ozone treated substrates at different dpi (scale bar: $100 \mu \mathrm{m}$ ): (b) 120 dpi and (c) 240 dpi. 
The stability of the ink properties and their jettability were followed for several months. As an example, after 4 months of storage of the Model ink in a closed amber flask, the optimum jetting conditions were the same as those of the freshly prepared ink. This test demonstrates the good stability of these photocurable hybrid organic-inorganic inks for this application.

Once the jetting conditions for stable droplet formation have been identified, the interaction of the drop, after landing, with the substrates has also been explored. In order to make functional devices, inkjet printing has to lead on one hand to well-defined patterns and on the other hand good adhesion of the final deposit to the underlying substrate. In our case, taking into account the hybrid nature of the inks studied, glass was cleaned and treated with two different protocols seeking for functional groups and textures that can promote adhesion of the reactive groups of the inks. In this way, clean glass was treated with UV-Ozone to eliminate surface contaminants leaving silanol groups exposed in the surface ${ }^{64}$. These hydroxyl groups can later react with the hydroxyl groups generated during the hydrolysis and condensation of the inks. Alternately CCVD using Pyrosil ${ }^{\circledR}$ was used to generate a nanoporous silanol rich surface that, as in the case of ozone treated glass, promotes adhesion to the glass through covalent bonding. The roughness added by the CCVD treatment additionally generates extra bonding surface that could further promote adhesion ${ }^{49}$.

Ink droplets were inkjet printed along a line in ozone treated substrates. If the spacing between droplets is large enough the result is a set of equally spaced dots on the substrate, as seen in Fig. 1b for HRI ink. If spacing is decreased, coalescence of droplets leading to continuous bead lines as shown in Fig. 1c. For certain dpi's around 240 dpi, stable lines are generated and bulging appears above certain dpi's for all the cases (> $300 \mathrm{dpi}$ ).

Printing of continuous area features using inks showing partial wetting, as in the present cases, has been achieved in other systems by sequential printing of spatially offset drop partially overlapping matrixes ${ }^{65}$. Given the architecture of our printhead, with a distance between nozzles of 137 microns, and the size of the printed dots, covering continuous areas using this approach would require printhead tilting with respect the substrate moving direction. Covering areas with ink can also be achieved by increasing the dpi in the substrate moving direction therefore producing line bulging and coalescence of contiguous lines, 
however this frequently leads to non-printed regions and faulty printing. Defect-free continuous areas have been achieved with our inks by using glass substrate treated with ozone or CCVD using pyrosil. While the preparation of defect-free areas using this approach on ozone treated substrates required the use of high dpi in the substrate moving direction (up to 1440 dpi and above), the strong ink spreading in the pyrosil treated substrates lead to continuous areas with uniform thickness at low dpi (e.g.: 360 dpi), although the definition of fine features is lost to some extent in the edges of the printed areas in this last case due to ink spreading.

Ink fixation. Continuous films of the Model ink were deposited on Pyrosil treated glass substrates using inkjet printing (360 dpi along the substrate moving direction). Irradiation of these films using UV light $\left(320-390 \mathrm{~nm}, 10 \mathrm{~mW} / \mathrm{cm}^{2}, 300 \mathrm{~s}\right)$ led to continuous solid films (3.5 $\mu \mathrm{m}$ thick). The films obtained are transparent and present a defect free morphology when observed by SEM (see Fig. S2) and under the optical microscope. AFM imaging of the film topography (Fig. S3) reveals a very smooth morphology with a root mean square (rms) surface roughness of $0.44 \mathrm{~nm}$ over a $4 \times 4 \mathrm{~m}^{2}$ area for a cured deposit of the Model ink.

UV-Vis absorption spectrum of a thin layer of the Model ink placed in quartz cells of fixed thickness (Fig. S4), shows an absorption band centered in $300 \mathrm{~nm}$ before irradiation with UV light. Exposure of the liquid layer leads to a depletion of this absorption that is ascribed to decomposition of the photoinitiator. This decomposition induces acid generation that triggers polymerization as mentioned above. Scheme 1 presents the epoxy ring-opening cationic photopolymerization. The photoacid $\mathrm{H}^{+} \mathrm{X}^{-}$generated on excitation of the photoinitiator, attacks the oxygen of the epoxy ring to initiate the formation of the polyether chain. Scheme 2 shows the photoacid-catalyzed sol-gel process for GPTMS that takes place first by hydrolysis of methoxysilane groups and later by condensation to form a siloxane chain. Differently from classical sol-gel reaction, this photoinduced sol-gel process, does not need any additional solvent (water or any other solvent) and simple diffusion of atmospheric moisture is sufficient for the hydrolysis reactions. 

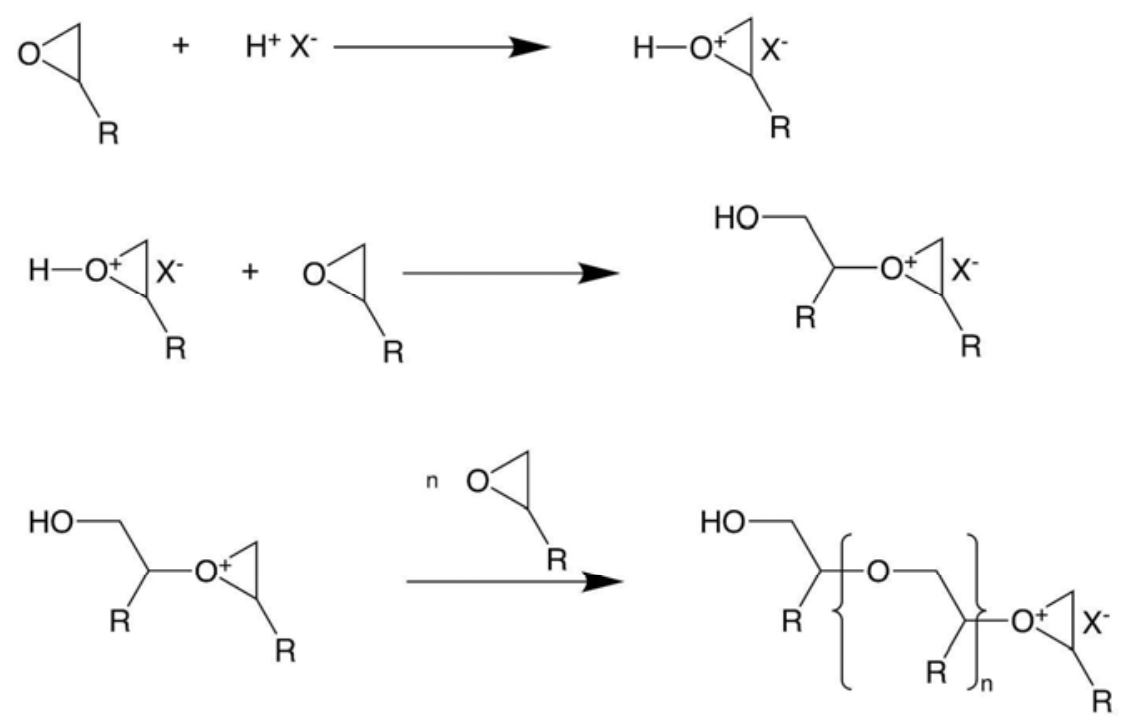

Scheme 1: Cationic ring opening polymerization of epoxy rings.

Hydrolysis
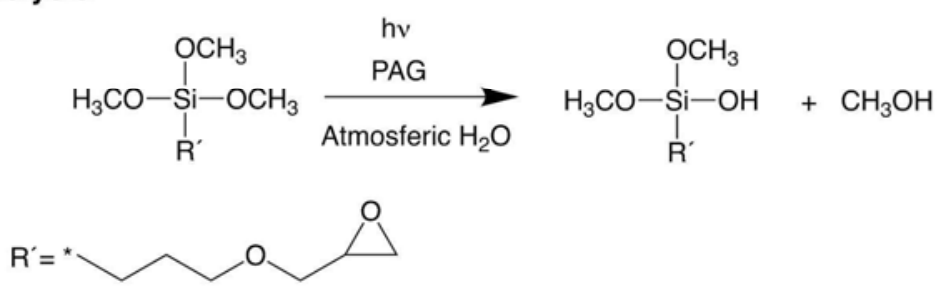

\section{Condensation}
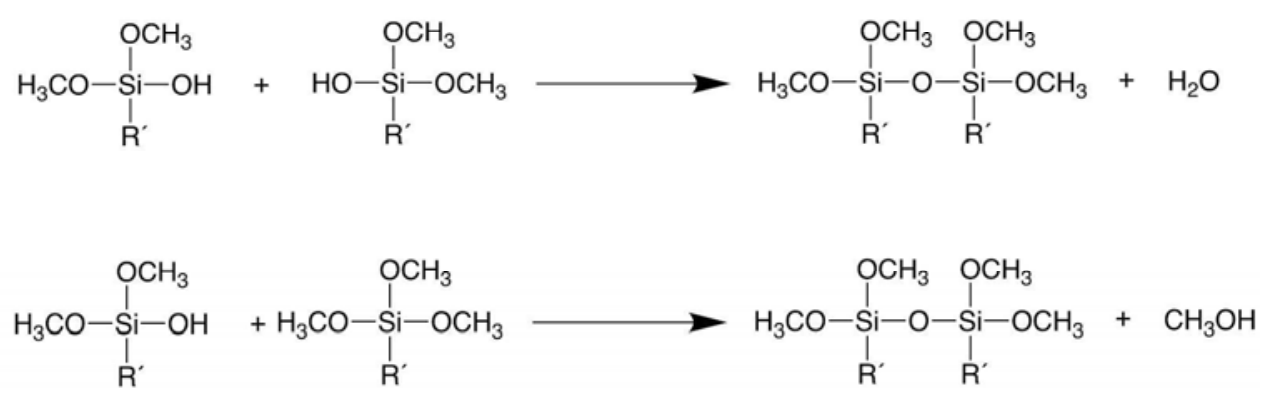

Scheme 2: Photoinduced sol-gel process (shown for GPTMS). Hydrolysis and condensation steps.

FTIR spectroscopy was employed to check the photoinduced polymerization reaction of the inks. Fig. 2 shows the FTIR spectra of the Model ink before and after exposure to UV light. The $\mathrm{C}-\mathrm{H}$ stretching band at $3050 \mathrm{~cm}^{-1}$ of the epoxide disappears indicating that UV irradiation promotes the epoxy ring opening reaction ${ }^{66}$ (see Scheme1). Regarding the inorganic polymerization, irradiation of the ink produces a noticeable growth of a wide band appearing at $3400 \mathrm{~cm}^{-1}$ corresponding with the vibration of the $\mathrm{OH}$ group in the $\mathrm{Si}-\mathrm{OH}$ bond, 
all this confirming the hydrolysis reaction ${ }^{67}$. On the other hand, the stretching vibration band assigned to the $\mathrm{Si}-\mathrm{O}-\mathrm{CH}_{3}$ group at $1080 \mathrm{~cm}^{-1}$, is replaced in the cured ink by a wider complex band with a peak at around $1100 \mathrm{~cm}^{-1}$ which can be attributed to the stretching vibrations of the siloxane Si-O-Si bonds. This confirms the occurrence of the condensation reaction, generating the inorganic network (see Scheme2). As a conclusion from these experiments, the excitation of the photoacid generator leads to, as previously reported Chemtob et al. ${ }^{58}$, two acid catalyzed processes simultaneously triggered in a single step curing process: on one side the cationic ring-opening polymerization of epoxide groups and on the other hand the hydrolysis and condensation of the silanes to form an inorganic silica network. Besides the films, the isolated deposited droplets and lines of Model ink described before can also be photopolymerized leading to stable transparent printed features (see Fig. S5).

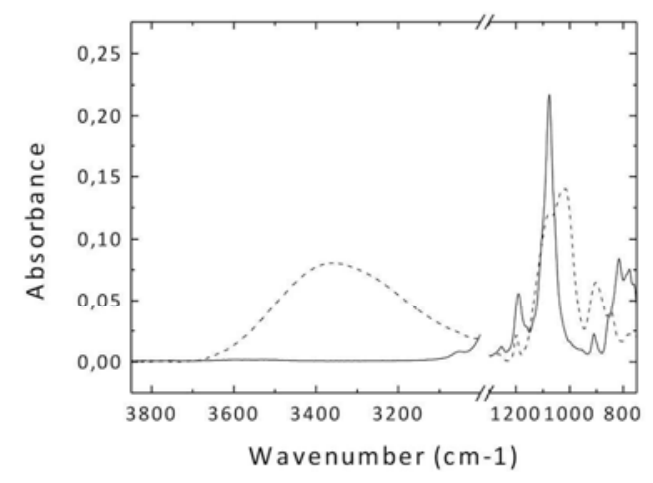

Fig. 2 FTIR spectra of Model ink before (continuous line) and 24h after exposure to UV light (dashed line).

Fixation of the HRI ink was also studied. Irradiation of the isolated deposited droplets in atmospheric curing conditions led to inhomogeneous textures as seen by phase contrast microscopy (Fig. S6 a and Fig. S6 b). Fig. 3a and Fig. 3b shows respectively a top view and a fractured cross-section of cured isolated printed droplets presenting morphologies that are associated to phase segregation during the photocuring process. Conversely, curing of thin films with thickness in the order of 4 micron or thicker of this same material also led to transparent films in the same curing conditions despite the edges of the printed area were again optically turbid. The SEM morphology of cured films (Fig. S7 a) reveals no inhomogeneities in the micron scale. 

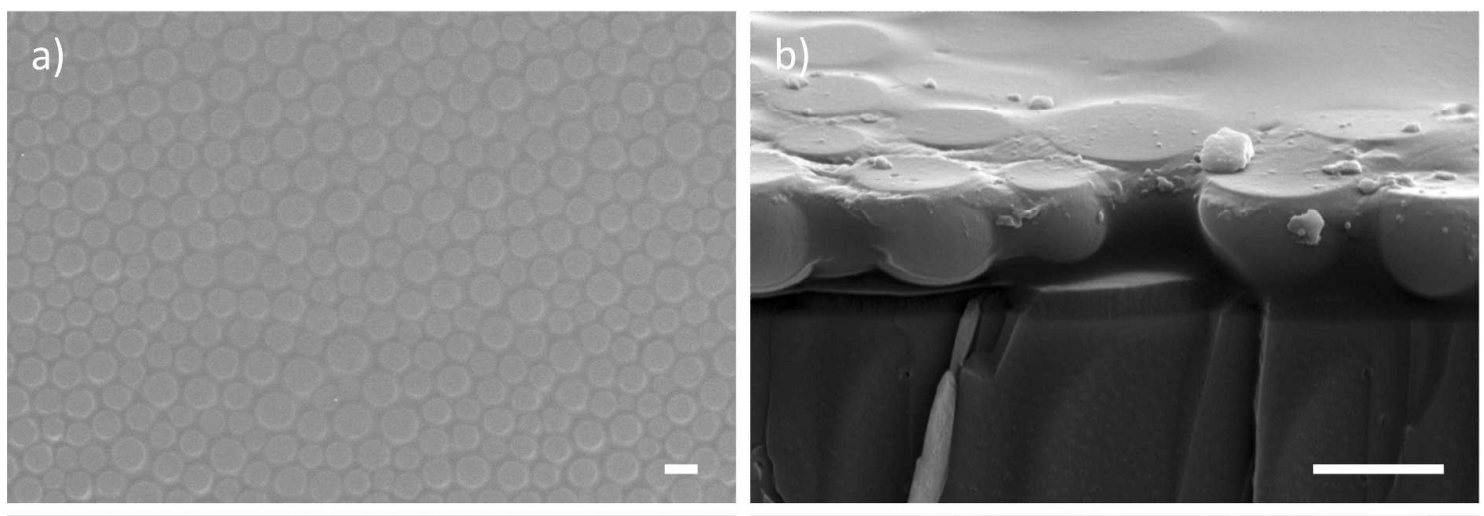

c)

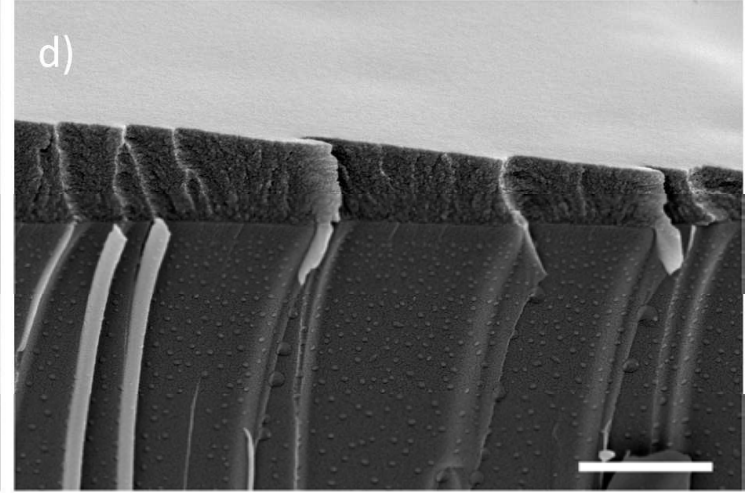

Fig. 3 SEM morphology of an isolated inkjet printed HRI droplet cured in ambient atmospheric conditions: (a) top view and (b) fractured cross section. (c) and (d) SEM morphology of an inkjet printed HRI droplet cured under mild vacuum conditions (100 mBar): (c) top view and (d) fractured cross section. (scale bar: $2 \mu \mathrm{m}$ ).

It is well known that polymerization kinetics in these UV cured hybrid systems is highly dependent on the presence of atmospheric water ${ }^{68}$. While the cationic reaction is not significantly influenced by the presence of atmospheric water ${ }^{69}$, this produces a strong effect in the inorganic network formation since water is needed for the hydrolysis reaction. Not only the amount of water available but also its ability to diffuse into the sample plays a very important role in the sol-gel polymerization. While thinner films in the order of microns usually lead to higher hydrolysis rates favoring the inorganic network formation, thicker ones have a slower supply of water to the deep layers reducing the photoacid catalyzed hydrolysis of the silane. Also the more difficult elimination of byproducts (alcohols) of the condensation in thicker films can induce a slow down of the hydrolysis ${ }^{58,68}$. On the other hand phase separation phenomena, leading to light scattering, has been observed in this type of photoacid catalyzed polymerization of hybrid systems. The presence of water and the formation of 
byproducts such as alcohols due to condensation can induce phase separation and formation of microsegregated phases ${ }^{58}$. Even more the balance between the formation rates of the two types of networks, organic and inorganic, is crucial to avoid phase segregation ${ }^{68}$.

The drastic reduction of turbidity found in the thicker films of the photocured HRI ink in ambient atmospheric conditions could indicate that the reduction of hydrolysis and condensation rates reduces the phase separation process. Since the ambient atmosphere is the water reservoir for the hydrolysis reaction, elimination of water from it could slow down the sol-gel process and minimize or inhibit phase separation.

To support this hypothesis, curing was carried out in a chamber provided with an optical access in which pressure was diminished to $100 \mathrm{mBar}$ to reduce the water content. Curing in these conditions of isolated deposited droplets of HRI ink led to microlenses free of the microsegregated morphology as observed by SEM (Fig. 3 c and Fig. 3d) and optical phase contrast microscopy (Fig. S6 c and Fig. S6 d). When thin films were inkjetted on glass substrates, highly transparent continuous films (even at the edges) in all the range of thickness under study were obtained (Fig. S7 b). AFM was also used to characterize the film topography. The cured films ( $4 \mu \mathrm{m}$ thick) have also a smooth morphology with a root mean square (rms) surface roughness of $1.92 \mathrm{~nm}$ and $1.03 \mathrm{~nm}$ over a $4 \mathrm{x} 4 \mu^{2}$ area for samples exposed in ambient atmospheric (Fig. S8 a) and under mild vacuum (Fig. S8 b) conditions respectively. This morphology was observed to be stable over periods of several, at least four, months.

FTIR spectroscopic studies were also carried out on the HRI ink to investigate the curing process in this system under the two considered curing conditions (Fig. 4). Focusing in the photoinduced formation of the inorganic network, which can be affected by the presence of atmospheric water, we have followed the bands at 3400 and $1100 \mathrm{~cm}^{-1}$ before and $10 \mathrm{~min}$ after UV irradiation. Under ambient atmospheric irradiation conditions (Fig. 4a), a wide band appears at around $3400 \mathrm{~cm}^{-1}$ ascribed to the formation of silanols that confirms the hydrolysis reaction. The peak at $1080 \mathrm{~cm}^{-1}$ due to the $\mathrm{Si}-\mathrm{O}-\mathrm{CH}_{3}$ group is replaced by a wide band appearing with a peak at around $1100 \mathrm{~cm}^{-1}$ associated to the siloxane bonds. This confirms that hydrolysis and condensation have already taken place 10 min after the UV irradiation has finished (see Scheme 2). Spectra taken $24 \mathrm{~h}$ later did not show significant qualitative differences (only minor changes around $1100 \mathrm{~cm}^{-1}$ ). The FTIR spectra just described (Fig. 4a) 
show similar qualitative features as those found for the GPTMS photopolymerization (Fig. 2) involving the same type of reactive groups and same curing conditions.

For the samples cured under mild vacuum conditions (Fig. 4b), the changes in the bands associated to the inorganic network followed a different dynamics. Just after the UV exposure under mild vacuum conditions, the sample is let to evolve in ambient atmosphere. FTIR spectrum at this point (10 min after UV exposure) reveals that the silanol band in the $3400 \mathrm{~cm}^{-1}$ region is already present few minutes after the sample is exposed to ambient atmosphere and later evolves shifting toward shorter wavenumbers (see spectrum at 24h). The bands around $1100 \mathrm{~cm}^{-1}$ also evolve in a different fashion. It can be seen that $10 \mathrm{~min}$ after the UV exposure the peak at $1080 \mathrm{~cm}^{-1}$ has decreased but the broad band at $1100 \mathrm{~cm}^{-1}$ continues later its evolution over the time. Note the relative absorbance change of the two different peaks around $1100 \mathrm{~cm}^{-1}$ between the spectra at $10 \mathrm{~min}$ and $24 \mathrm{~h}$ that indicates that condensation significantly takes place after the first $10 \mathrm{~min}$ for the sample cured under mild vacuum conditions, in contrast to the lack of evolution observed for the sample exposed in ambient atmospheric conditions. After $24 \mathrm{~h}$ the spectra does not qualitatively evolve as followed during one month. Despite the differences in dynamics observed between the samples cured under the two different conditions, the spectra of both films presented qualitatively the same spectra features after $24 \mathrm{~h}$. The differences in the reaction kinetics under these two different curing conditions are responsible for the large differences in morphology for the isolated cured droplets. The experiments above highlight the importance of the presence and the supply of water to the reaction to control the formation of the organic and inorganic networks and therefore the film morphology ${ }^{67}$. Since no evolution of the FTIR spectra was observed for periods of time longer than $24 \mathrm{~h}$, all the films were allowed to evolve in darkness for at least $24 \mathrm{~h}$ before any subsequent characterization to ensure completion of the hydrolysis and condensation process. 

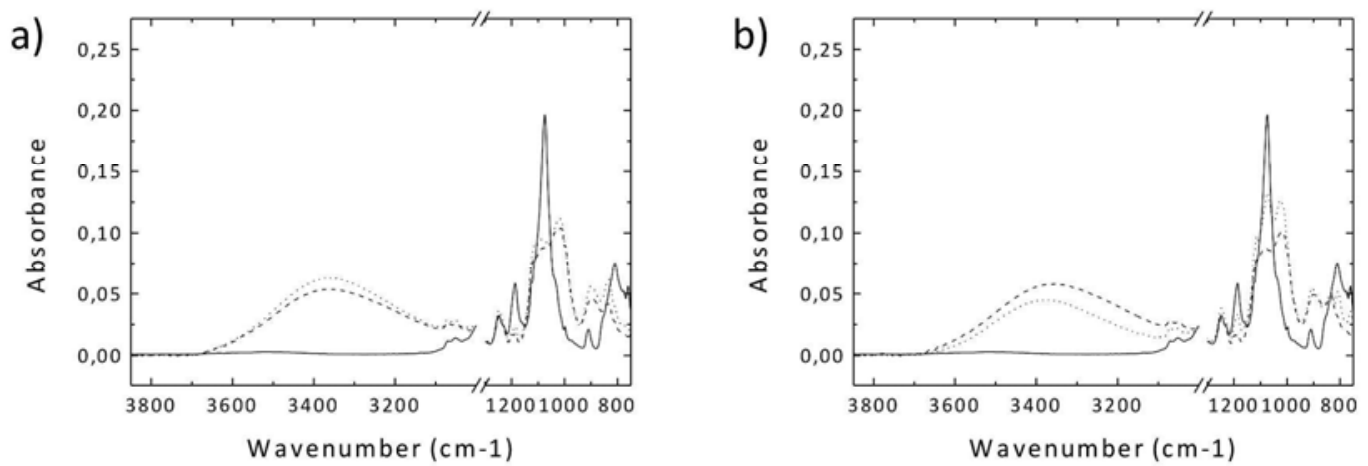

Fig. 4 FTIR spectra of HRI ink before (continuous line), 10 min after (dotted line) and 24h after exposure to UV light (dashed line) (a) in ambient atmosphere conditions and (b) under mild vacuum conditions (100 mBar).

\section{Mechanical properties and adhesion to the substrate}

To assess the mechanical properties of the deposited films, elastic modulus and hardness were measured using a nanoindenter. Nanoindentation is a suitable technique to determine mechanical properties of these type of hybrid organic-inorganic films ${ }^{70}$. Larger load was necessary for the HRI ink based deposits to reach the $400 \mathrm{~nm}$ indentation depth, independently of the curing method, when compared to the Model ink ones that indicates a higher elastic modulus of the HRI deposits. The Young Modulus (E) and hardness (H) obtained for the Model and HRI ink deposits are given in Table 3.

Table 3. Mean values for the Young Modulus (E) and hardness (H).

\begin{tabular}{|l|l|}
\hline & $\mathrm{E}(\mathrm{GPa}) / \mathrm{H}(\mathrm{GPa})$ \\
\hline Model ink & $2.6 / 0.19$ \\
\hline HRI ink (cured in ambient atmospheric conditions) & $4.7 / 0.31$ \\
\hline HRI ink (cured under mild vacuum conditions) & $4.7 / 0.30$ \\
\hline
\end{tabular}

The value of Young modulus of $2.6 \mathrm{GPa}$ for the inkjet printed deposits cured using the photoacid catalyzed curing agrees with other values found in literature for GPTMS networks 
despite cured following a different method ${ }^{70,71}$. Higher values of the Young modulus were obtained for the HRI ink what can be ascribed to the presence of multifunctional Epikote 157 and APDMS in the formulation leading also to a strongly crosslinked network. No significant differences were found in the mechanical properties between films measured at different times after curing within three months (samples stored in ambient atmosphere) indicating good mechanical stability of the deposited films.

Concerning adhesion to glass, the SEM images of fractured samples (Fig. 3), demonstrated excellent adhesion between the cured inks and the glass substrate. To assess the adhesion of the deposited materials towards the substrate, cross-cut and tape tests based on the standard ASTM 3359 were carried out. Optical microscope images of cross-cut areas after the test (film thickness: 3.5-4.5 $\mu \mathrm{m}$ ) were taken. For the Model ink deposited on glass previously treated with pyrosil, and cured immediately after deposition (Fig. S9 a), almost all the film remained attached after the adhesion test carried out one day after the curing step. Detaching of small flakes along the edges of the cut is observed in the samples with an estimated affected area below 5\% and therefore being rated as 4B-5B binding strength, demonstrating a good adhesion of the inkjet printed deposits to the glass substrate. For the HRI ink (Fig. S9 b and Fig. S9 c) almost no delamination was observed, being the adhesion strength rating assigned 4B-5B for these films regardless the photocuring protocol adopted (atmospheric or mild vacuum conditions). The tests were repeated in all the samples, stored in ambient conditions, 3 months later finding similar results.

\section{Inkjet printed planar waveguides}

Deposits of the Model and HRI inks were directly prepared by inkjet printing on top of glass substrates and subsequently exposed to UV light. As described above, the films presented a stable transparent, defect-free morphology with smooth surface topography, which is a prerequisite in waveguide applications (see Fig. S3 and Fig. S8). Coupling of waveguided modes was demonstrated in our inkjet films of hybrid materials by using the prism coupling technique using $632.8 \mathrm{~nm}$ light. This technique enables the characterization of the refractive index and thickness of these so prepared thin films. As an example, Fig. 5a and 5b shows that a thin film of HRI ink cured at reduced pressure supports several Transversal Electric (TE) and Transversal Magnetic (TM) modes. Only the indicated intensity drops, corresponding to modes with effective refractive index higher than that of the substrate $\left(\mathrm{n}_{\mathrm{g}}=1.514\right)$, are fully 
supported by the inkjetted film, corresponding the rest of the intensity drops to substrate modes. The effective refractive index of the film modes were used for the calculation of the film refractive index and its thickness ${ }^{55}$. Refractive index of 1.560 and thickness of $4.2 \mu \mathrm{m}$ are calculated from these measurements for the HRI film exposed at reduced pressure. This is in good agreement with the deposit thickness measured using stylus profilometry (4 $\mu \mathrm{m}$ thick). High values of the refractive index, suitable for waveguide preparation arise from the aromatic components of the HRI. Thicker films were also prepared with these materials by inkjet leading to planar waveguide supporting a large number of modes (see Fig. S10). The same characterization was carried out for thin film deposits of the HRI ink cured in ambient atmospheric conditions (Fig. S11) and of the model ink (Fig. S12).

a)

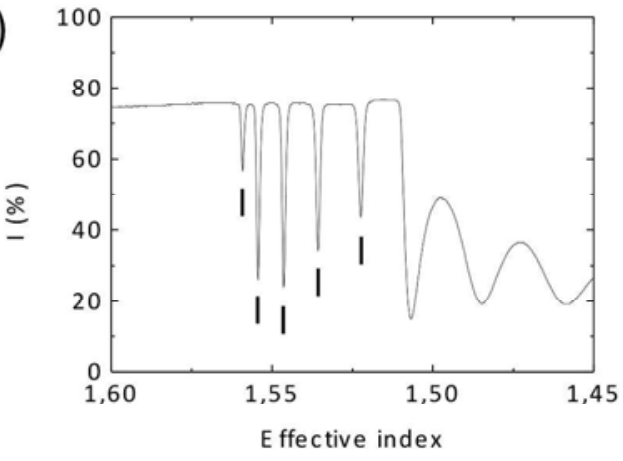

c)

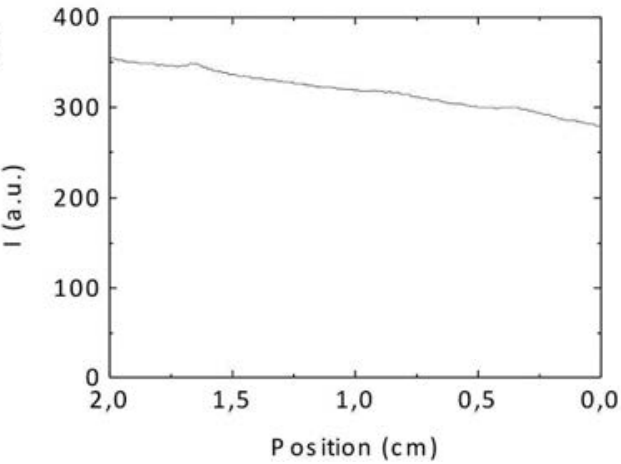

b)
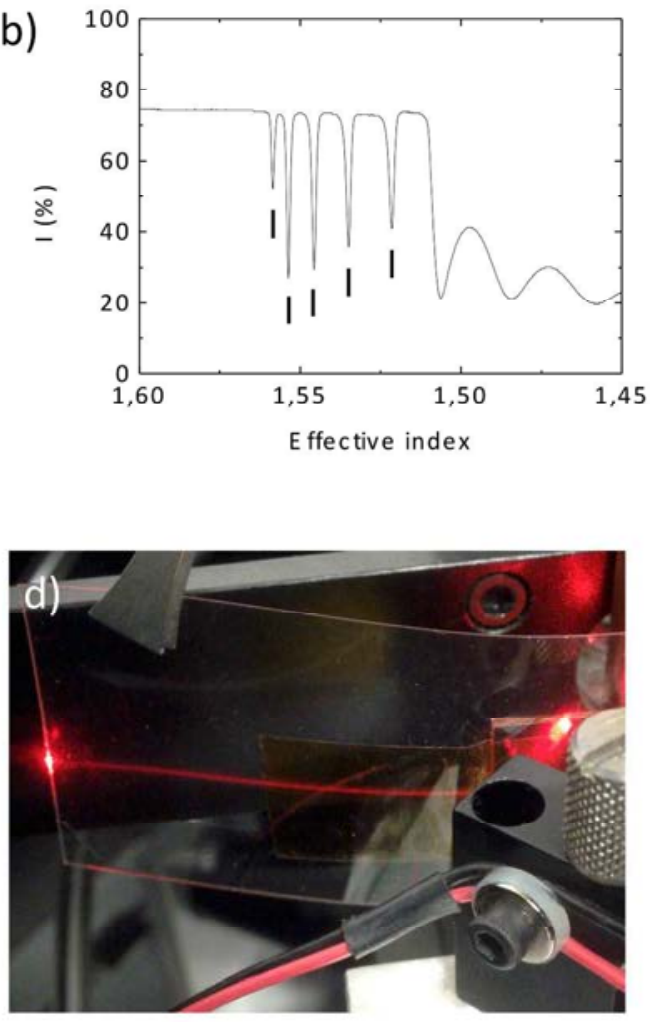

Fig. 5 (a) TE and (b) TM propagation modes (at $632.8 \mathrm{~nm}$ ) for a HRI ink deposit $(4 \mu \mathrm{m}$ thick) cured under mild vacuum conditions. Modes with effective refractive index higher than that of the substrate $\left(n_{g}=1.514\right)$, and fully supported by the inkjetted film are indicated with a line. (c) Intensity distribution along an inkjet printed waveguide of HRI ink cured under mild vacuum conditions. (d) Scattered light streak from an inkjet printed waveguide from HRI ink on a flexible PET substrate with a Model ink printed cladding layer. The substrate and waveguide are bent with the help of a pair of tweezers (top-left). 
To assess the performance of the deposits as planar waveguides we have characterized the optical propagation losses of the TE0 mode at $632.8 \mathrm{~nm}$. To do this, the scattered light from this mode at each point of the waveguide (Fig. 5c) is measured using a fiber photodetector that moves along the surface following the propagation direction. This enables to estimate propagation losses by fitting the signal to exponential decay. Optical transmission losses of 0.5-0.6 $\mathrm{dB} / \mathrm{cm}$ at $632.8 \mathrm{~nm}$ have been measured for samples exposed under mild vacuum conditions. On the other hand those cured in ambient atmospheric conditions led typically to $1-1.1 \mathrm{~dB} / \mathrm{cm}$. In both cases loss coefficients were stable over periods of 2 months.

Since there is no detectable absorption at the wavelength of measurement (Fig. S4), the losses have their origin mainly in scattering coming from refractive index spatial variations either from the surface or the volume of the waveguide. Optical losses related to surface variations are proportional to the rms surface roughness ${ }^{72}$. The morphology studies carried out using AFM already showed that the different curing conditions led to differences in smoothness of the cured deposits with rms surface roughness is $1.03 \mathrm{~nm}$ and $1.92 \mathrm{~nm}$ for HRI film cured under mild vacuum and in ambient atmospheric conditions respectively. Despite these roughness values are similar to, even smaller than, those obtained in other materials by using techniques other than inkjet printing, for this same application, the overall losses are larger in our case ${ }^{16,17,20}$. In this way, Yoon et al. prepared channel waveguides by patterned UV photopolymerization of ORMOCER materials with rms surface roughness of 2 to $5 \mathrm{~nm}$ and propagation losses as small as $0.07 \mathrm{~dB} / \mathrm{cm}$ (measured at $850 \mathrm{~nm})^{20}$. As a result, light losses due to scattering in the bulk has to be a relevant contribution in our case. The losses due to bulk scattering have their origin at spatial variations of refractive index arising from density or compositional spatial modulations. In our system we have found that the ratio between the cationic polymerization rate and that of the hydrolysis and condensation strongly affects the microscopic morphology and therefore the scattering properties of the cured material. Consequently kinetics is very important in optimizing the performance of thin films of this type of materials as optical waveguides. Because of this, polymerization conditions, that is UV light intensity and the humidity during the process, are key parameters seeking to minimize these losses and to improve the performance of the inkjet printed waveguides. 
To exploit the ability of inkjet printing technology to deposit different materials, planar waveguides were manufactured by applying a cladding consisting on a film of Model ink (3.5 $\mu \mathrm{m}$ thick). Once cured, on top of this layer a second deposit of HRI ink (4 $\mu \mathrm{m}$ thick) was inkjet printed and photocured acting as the core of the planar waveguide. These structures demonstrated to support waveguiding modes with low losses when applied on glass plates. This low attenuation values for the light propagating through the top waveguide were also obtained when flexible Polyethylene terephthalate (PET) film used in flexible electronics was employed or even conventional ceramic glass and metallic substrates industrially used in conventional applications such as home-appliances like cooktops, fridge or dishwasher front doors. In particular, the deposited waveguides on flexible PET substrates are mechanically stable against bending showing neither detachment or cracking (Fig. 5d) nor increment in propagation losses after ceasing the bending. The lower refractive index cladding applied on top of the rough surface planarizes it and act as a flat substrate for waveguide core manufacturing. These experiments emphasize the versatility and power of these materials in combination with inkjet printing technology to generate optical circuits in a wide variety of substrates.

Finally, beyond planar waveguides, channel waveguides with different widths have been also printed with these materials on glass substrates to highlight the potential of these fabrication platform to prepare photonic devices. Fig. 6 shows photographs and profiles of inkjet printed HRI waveguides, cured under mild vacuum conditions. Channel waveguides with different widths were prepared in ozone treated substrates. One single-pixel width channel waveguides were obtained by printing ink droplets along a line with a spacing between droplets of 240 dpi. As mentioned above, stable lines (Fig. 6a, left-side waveguide; Fig. 6b, left-side profile) can be obtained. Wider channel waveguides of three-pixel width were prepared by first using two alternate nozzles (with one inactive nozzle in between) to generate, in a first pass, two lines as the one described just above (at $240 \mathrm{dpi}$ ). In a second pass, the nozzle in between the two used in the first pass, is used to fill the empty space in between the two lines previously printed depositing a large amount of ink (at $4320 \mathrm{dpi}$ ), leading to a channel waveguide with high profile (Fig. 6a, central waveguide; Fig. 6b, central profile). Wider waveguides, for example five-pixel width (Fig. 6a, right-side waveguide; Fig. 6b, right-side profile), can be prepared using a homologous strategy based on the use of alternate nozzles and two printing passes. After the curing step, light was coupled in these waveguides and losses as low as 0.5 $\mathrm{dB} / \mathrm{cm}$ at $632.8 \mathrm{~nm}$ have been measured (Fig. 6c). 

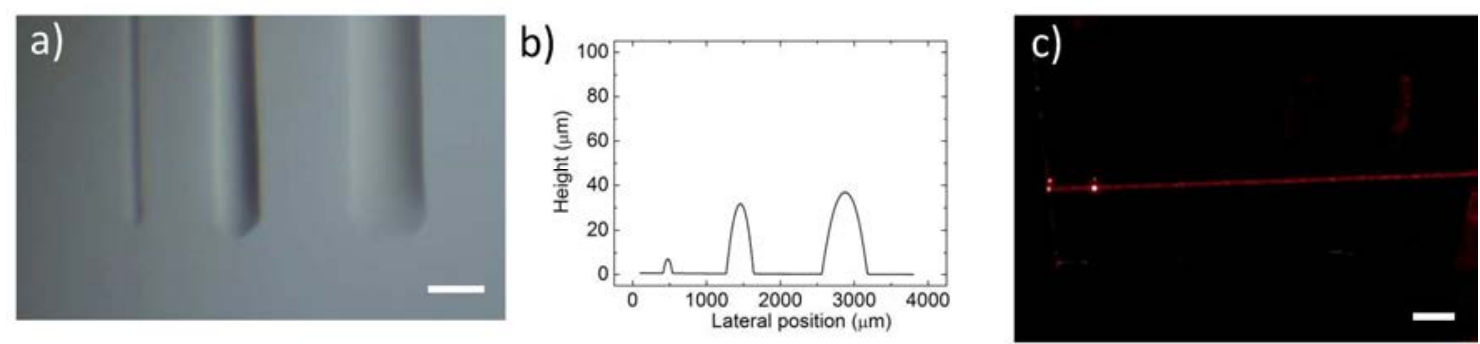

Fig. 6. (a) HRI channel waveguides of different widths (1, 3 and 5 pixels) inkjet printed on a glass substrate (scale bar: $500 \mu \mathrm{m}$ ). (b) Cross section profiles of the waveguides. (c) Scattered light streak from a three-pixel width inkjet printed channel waveguide. Light is coupled in using a prism placed in the right (not shown in the figure) (scale bar: $500 \mu \mathrm{m}$ ).

Putting the obtained values in perspective with respect to other works in the literature, channel waveguides generated by inkjet of SU-8 solutions by Vacirca and Kurzweg resulted in losses $16.1 \mathrm{~dB}$ in $7.5 \mathrm{~cm}^{73}$. Channel waveguides created by inkjet printing a solvent etchant on a thin film of polystyrene led to optical losses of $2 \mathrm{~dB} / \mathrm{cm}^{74}$. The values obtained in the inkjet printed planar waveguides presented in our work, in the order of $0.5-0.6 \mathrm{~dB} / \mathrm{cm}$, are in the same range of values of others obtained by other processing techniques ${ }^{75,76}$ despite improvements in composition and processing are still needed to reach the values, as low as $0.07 \mathrm{~dB} / \mathrm{cm}$, obtained by using photolithography in Ormocore materials ${ }^{20}$.

\section{Conclusions}

Jettable inks based on photoacid catalyzed formulations containing monomers with epoxy and silane functionalities has been successfully formulated. Compared to inks based on conventional sol-gel processes, the hydrolysis and condensation in these materials is advantageously delayed in the absence of UV light favoring the long-term stability of the ink properties, mainly viscosity, essential for their applicability in industrial applications. Due to the lack of solvents in the ink formulation, the deposited material can be polymerized immediately after the ink deposition with UV light and without the need of intermediate baking steps significantly simplifying the process and leading to functional deposits in one single step, allowing also the use of thermally sensitive substrates. UV light triggers the photocuring reaction of the epoxy groups and in the presence of water a crosslinked organicinorganic polymeric network is obtained. A proper selection of the curing conditions enables to obtain, through a simple process, without the need of postbaking steps, deposits with 
excellent adhesion to glass and good transparency. Planar and channel waveguides that support modes with propagation losses as low as $0.5 \mathrm{~dB} / \mathrm{cm}$ have been demonstrated with this approach. The results here obtained of low attenuation of the propagating light for inkjet printed photocured hybrid waveguides and the possibility to use substrates of different nature demonstrate the suitability of these photoacid catalyzed hybrid formulations and inkjet printing for the preparation photonic devices.

\section{Ackowledgements}

Carlos Sánchez-Somolinos thanks the Spanish MINECO project SAF2014-54763-C2-2-R, Gobierno de Aragón, and FEDER (EU). Authors would like to acknowledge the use of Servicio General de Apoyo a la Investigación-SAI, Universidad de Zaragoza. 


\section{References}

1. R. Hunsperger, Integrated Optics, theory and technology, 6th ed, Springer-Verlag, New York, 2009.

2. C. Sánchez, B. Lebeau, F. Chaput and J. P. Boilot, Adv. Mater., 2003, 15, 1969-1994.

3. M. Foerthner, M. Rumler, F. Stumpf, R. Fader, M. Rommel, L. Frey, M. Girschikofsky, S. Belle, R. Hellmann and J. J. Klein, Appl. Phys. A, 2016, 122-240.

4. J. A. Grant-Jacob, S. J. Beecher, T. L. Parsonage, P. Hua, J. I. Mackenzie, D. P. Shepherd and R. W. Eason, Opt. Mater. Express, 2016, 6, 91-96.

5. S. Nizamoglu, M. C. Gather, M. Humar, M. Choi, S. Kim, K. S. Kim, S. K. Hahn, G. Scarcelli, M. Randolph, R. W. Redmond and S. H. Yun, Nat. Commun., 2016, 7, 10374.

6. S. Parola, B. Julián-López, L. D. Carlos and C. Sanchez, Adv.Funct.Mater., 2016, 26, 6506-6544.

7. Y. Sun, Q. Liao, Y. Huang, A. Xia, Q. Fu, X. Zhu and Y. Zheng, Bioresour. Technol., 2016, 220, 215-224.

8. S. Guy, B. Baguenard, A. Bensalah-Ledoux, D. Hadiouche and L. Guy, ACS Photonics, 2017, DOI: 10.1021/acsphotonics.7b00975.

9. H. K. Kim, S.-J. Kang, S.-K. Choi, Y.-H. Min and C.-S. Yoon, Chem. Mater., 1999, 11, 779-788.

10. P. Coudray, P. Etienne, Y. Moreau, J. Porque and S. I. Najafi, Opt. Commun., 1997, 143, 199-202.

11. R. Houbertz, L. Fröhlich, M. Popall, U. Streppel, P. Dannberg, A. Bräuer, J. Serbin and B. N. Chichkov, Adv. Eng. Mater., 2003, 5, 551-555.

12. P. Coudray, P. Etienne and Y. Moreau, Mater. Sci. Semicond. Process., 2000, 3, 331337.

13. E. J. Nassar, R. R. Gonçalves, M. Ferrari, Y. Messaddeq and S. Ribeiro, J. Alloys Compd., 2002, 344, 221-225.

14. W. Que and X. Hu, J. Sol-Gel Sci. Technol., 2003, 28, 319-325.

15. R. Houbertz, G. Domann, C. Cronauer, A. Schmitt, H. Martin, J. U. Park, L. Fröhlich, R. Buestrich, M. Popall, U. Streppel, P. Dannberg, C. Wächter and A. Bräuer, Thin Solid Films, 2003, 442, 194-200.

16. W. Que, X. Hu and J. Zhou, Thin Solid Films, 2005, 484, 278-282.

17. P. Karasiński, C. Tyszkiewicz, A. Domanowska, A. Michalewicz and J. Mazur, Mater. Lett., 2015, 143, 5-7. 
18. A. Serra, X. Ramis and X. Fernández-Francos, Coatings, 2016, 6, 8-19.

19. K. H. Haas, S. Amberg-Schwab and K. Rose, Thin Solid Films, 1999, 351, 198-203.

20. K. B. Yoon, Macromol. Res., 2004, 12, 290-292.

21. R. Woods, S. Feldbacher, D. Zidar, G. Langer, V. Satzinger, V. Schmidt, N. Pucher, R. Liska and W. Kern, Opt. Mater. Express, 2014, 4, 486-498.

22. G. Brusatin, D. G. Giustina, M. Guglielmi, M. Casalboni, P. Prosposito, S. Schutzmann and G. Roma, Mater. Sci. Eng. C, 2007, 27, 1022-1025.

23. J. Alamán, R. Alicante, J. Peña and C. Sánchez-Somolinos, Materials, 2016, 9, 910 947.

24. M. Singh, H. M. Haverinen, P. Dhagat and G. E. Jabbour, Adv. Mater., 2010, 22, $673-685$.

25. B. Derby, Annu. Rev. Mater. Res., 2010, 40, 395-414.

26. M. Robin, W. Kuai, M. Amela-Cortes, S. Cordier, Y. Molard, T. Mohammed-Brahim, E. Jacques and M. Harnois, ACS Appl. Mater. Interfaces, 2015, 7, 21975-21984.

27. R. Danzebrink and M. A. Aegerter, Thin Solid Films, 1999, 351, 115-118.

28. R. Danzebrink and M. A. Aegerter, Thin Solid Films, 2001, 392, 223-225.

29. J. Y. Kim, N. B. Brauer, V. Fakhfouri, D. L. Boiko, E. Charbon, G. Grützner and J. Brugger, Opt. Mater. Express, 2011, 1, 259-269.

30. J. Y. Kim, K. Pfeiffer, A. Voigt, G. Gruetzner and J. Brugger, J. Mater. Chem., 2012, 22, 3053-3058.

31. J. Y. Kim, C. Martin-Olmos, N. S. Baek and J. Brugger, J. Mater. Chem. C, 2013, 1, 2152-2157.

32. L. Jacot-Descombes, V. J. Cadarso, A. Schleunitz, S. Grützner, J. J. Klein, J. Brugger, H. Schift and G. Grützner, Opt. Express, 2015, 23, 25365-25376.

33. A. Voigt, U. Ostrzinski, K. Pfeiffer, J. Y. Kim, V. Fakhfouri, J. Brugger and G. Gruetzner, Microelectron. Eng., 2011, 88, 2174-2179.

34. S. T. Parker, P. Domachuk, J. Amsden, J. Bressner, J. A. Lewis, D. L. Kaplan and F. G. Omenetto, Adv. Mater., 2009, 21, 2411-2415.

35. A. Samusjew, M. Kratzer, A. Moser, C. Teichert, K. K. Krawczyk and T. Griesser, ACS Appl. Mater. Interfaces, 2017, 9, 4941-4947.

36. D. J. Lorang, D. Tanaka, C. M. Spadaccini, K. A. Rose, N. J. Cherepy and J. A. Lewis, Adv. Mater., 2011, 23, 5055-5058.

37. T. Wolfer, P. Bollgruen, D. Mager and L. Overmeyer, Procedia Technol., 2014, 15, 521-529. 
38. T. Wolfer, P. Bollgruen, D. Mager, L. Overmeyer and J. G. Korvink, Mechatronics, 2016, 34, 119-127.

39. M. Hofmann, Y. Xiao, S. Sherman, P. Bollgrün, T. Schmidt, U. Gleissner and H. Zappe, Inkjet printed single-mode waveguides on hot-embossed foils, Proc. of SPIE Optical Systems Design, Jena, Germany, 2015.

40. P. Bollgruen, U. Gleissner, C. Megnin, D. Mager, J. Korvink and T. Hanemann, Inkjet printing of host-guest systems based on acrylates with fluorescent dopants, Proc. SPIE 9888 Micro-Optics, Brussels, Belgium, 2016.

41. P. Bollgruen, U. Gleissner, T. Wolfer, C. Megnin, D. Mager, L. Overmeyer, J. G. Korvink and T. Hanemann, Opt. Eng., 2016, 55, 107107.

42. P. Bollgruen, T. Wolfer, U. Gleissner, D. Mager, C. Megnin, L. Overmeyer, T. Hanemann and J. G. Korvink, Flex. Print. Electron., 2017, DOI: 10.1088/20588585/aa8ed6.

43. E. Amerio, M. Sangermano, G. Malucelli, A. Priola and B. Voit, Polymer, 2005, 46, 11241-11246.

44. E. Amerio, M. Sangermano, G. Malucelli, A. Priola and G. Rizza, Macromol. Mater. Eng., 2006, 291, 1287-1292.

45. M. Sangermano, M. Messori, M. M. Galleco, G. Rizza and B. Voit, Polymer, 2009, 50, 5647-5652.

46. A. Chemtob, M. Peter, C. Belon, C. Dietlin, C. Croutxé-Barghorn, L. Vidal and S. Rigolet, J. Mater. Chem., 2010, 20, 9104-9112.

47. C. Croutxè-Barghon, C. Belon and A. Chemtob, J. Photopolym. Sci. Technol., 2010, 23, 129-134.

48. C. Belon, A. Chemtob, C. Croutxé-Barghorn, S. Rigolet, M. Schmitt, S. Bistac, V. Le Houérou and C. Gauthier, Polym. Int., 2010, 59, 1175-1186.

49. B. Schuhmacher, W. Müschenborn, M. Stratmann, B. Schultrich, C.-P. Klages, M. Kretschmer, U. Seyfert, F. Förster and H.-J. Tiller, Adv. Eng. Mater., 2001, 3, 681-689.

50. W. C. Oliver and G. M. Pharr, J. Mater. Res., 1992, 7, 1564-1583.

51. C. Belon, A. Chemtob, C. Croutxé-Barghorn, S. Rigolet, V. Le Houérou and C. Gauthier, J. Polym. Sci. A Polym. Chem., 2010, 48, 4150-4158.

52. C. Belon, A. Chemtob, C. Croutxé-Barghorn, S. Rigolet, V. Le Houérou and C. Gauthier, Macromol. Mater. Eng., 2011, 296, 506-516.

53. A. C. Fischer-Cripps, Surf. Coat. Technol., 2006, 200, 4153-4165. 
54. Standard ASTM D3359-02, Standard Test Methods for Measuring Adhesion by Tape Test, West Conshocken, PA, USA: 2002.

55. C. X. Tong, in Advanced Materials for Integrated Optical Waveguides, Springer International Publishing, Switzerland, $1^{\text {st }}$ edition, 2014, 46, 53-102.

56. J. V. Crivello, J. Polym. Sci. Part A: Polym. Chem., 1999, 37, 4241- 4254.

57. S. Shi, C. Croutxé-Barghorn and X. Allonas, Prog. Polym. Sci., 2017, 65, 1-41.

58. A. Chemtob, D.-L. Versace, C. Belon, C. Croutxé-Barghorn and S. Rigolet, Macromolecules, 2008, 41, 7390-7398.

59. B. Derby, N. Reis, K. Seerden, P. S. Grant and J. Evans, MRS Proc., 2000, 625, $195-$ 201.

60. D. Jang, D. Kim and J. Moon, Langmuir, 2009, 25, 2629-2635.

61. P. C. Duineveld, M. M. de Kok, M. Buechel, A. Sempel, K. A. Mutsaers, P. van de Weijer, I. G. Camps, T. van de Biggelaar, J.-E. J. Rubingh and E. I. Haskal, Proc. SPIE, 2002, 4464, 59-67.

62. S. D. Hoath, I. M. Hutchings, G. D. Martin, T. R. Tuladhar, M. R. Mackley and D. Vadillo, J. Imaging Sci. Technol., 2009, 53, 041208.

63. S. D. Hoath, D. C. Vadillo, O. G. Harlen, C. McIlroy, N. F. Morrison, W.-K. Hsiao, T. R. Tuladhar, S. Jung, G. D. Martin and I. M. Hutchings, J. Non-Newton. Fluid Mech., 2014, 205, 1-10.

64. C. K. Fink, K. Nakamura, S. Ichimura and S. J. Jenkins, J. Phys.: Condens. Matter, 2009, 21, 183001-183020.

65. E. Tekin, B.-J. de Gans and U. S. Schubert, J. Mater. Chem., 2004, 14, 2627-2632.

66. A. Chemtob, L. Ni, C. Dietlin, C. Croutxé-Barghorn, P. Kitzmann, M. Brogly and L. Vidal, Surf. Coat. Technol., 2012, 209, 64-72.

67. H. De Paz, A. Chemtob, C. Croutxé-Barghorn, D. Le Nouen and S. Rigolet, J. Phys. Chem. B, 2012, 116, 5260-5268.

68. L. Ni, N. Moreau, A. Chemtob and C. Croutxé-Barghorn, J. Sol-Gel Sci. Technol., 2012, 64, 500-509.

69. M. Sangermano, N. Razza and J. V. Crivello, Macromol. Mater. Eng., 2014, 299, $775-793$.

70. F. Mammeri, E. L. Bourhis, L. Rozes and C. Sanchez, J. Mater. Chem., 2005, 15, $3787-3811$.

71. M. A. Robertson, R. A. Rudkin, D. Parsonage and A. Atkinson, J. sol-gel Sci. Technol., 2003, 26, 291-295. 
72. F. P. Payne and J. A. Lacey, Opt. Quant. Electron., 1994, 26, 977-986.

73. N. A. Vacirca and T. P. Kurzweg, in Advanced Fabrication Technologies for Micro/Nano Optics and Photonics III, ed. W. V. Schoenfeld, J. J. Wang, M. Loncar and T. J. Suleski, Society of Photo-Optical Instrumentation Engineers (SPIE), San Francisco, 2010, 7591, 75910A-75910A8.

74. C. Zhang, C. L. Zou, Y. Zhao, C. H. Dong, C. Wei, H. Wang, Y. Liu, G. C. Guo, J. Yao and Y. S. Zhao, Sci. Adv., 2015, 1, e1500257.

75. V. Prajzler, P. Hyps, R. Mastera and P. Nekvindova, Radioengineering, 2016, 25, $230-235$.

76. D. Hadiouche, C. Le Luyer, L. Guy, A. Bensalah-Ledoux, S. Saoudi, H. Khireddine and S. Guy, Opt. Mater. 2014, 36, 885-891. 
TOC entry for "Photoacid catalyzed organic-inorganic hybrid inks for the manufacturing of Inkjet-Printed Photonic Devices" by Jorge Alamán et al.:

\section{Photoacid catalyzed organic-inorganic hybrid inks}
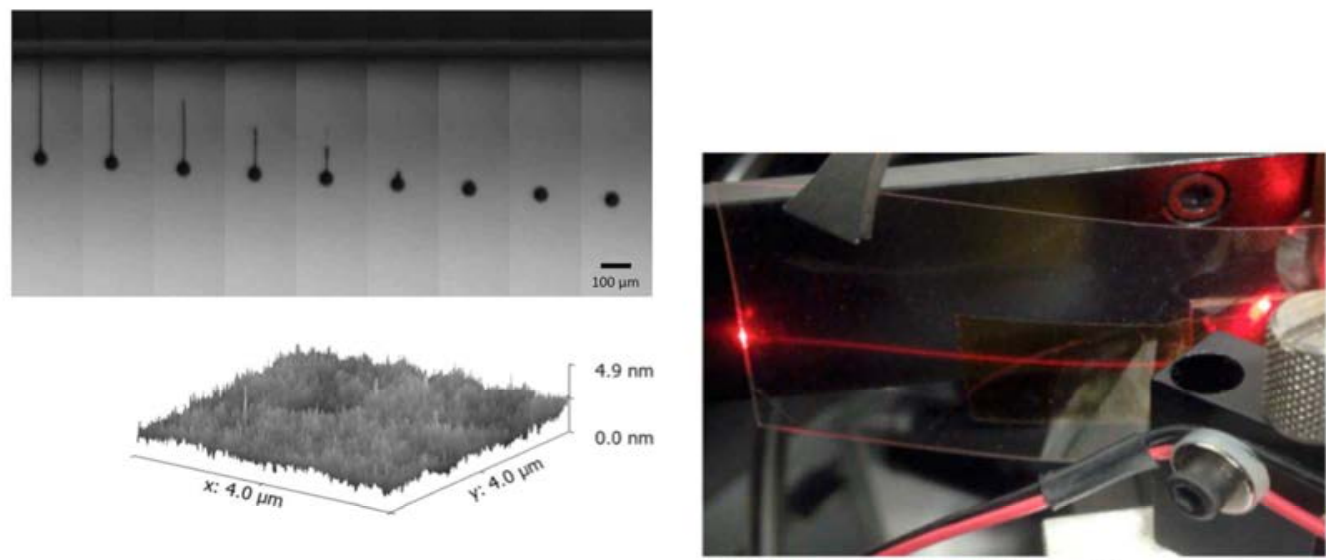

Inkjet-Printed Planar Waveguides

Inkjet printing of photoacid catalyzed organic-inorganic hybrid formulations have been been used in the preparation of low-loss optical waveguides 